\title{
Boundaries Through the Prism of Post-secondary and Professional Orientation: The Views of Young Québec Adults of Immigrant Background
}

\author{
Fahimeh Darchininan ${ }^{1}$ Marie-Odile Magnan ${ }^{2}$ \\ Université de Montréal, Canada
}

\begin{abstract}
Based on our collection of life stories $(\mathrm{n}=25)$, our qualitative study seeks to better understand, after the fact, how young, immigrantbackground adults in Québec negotiate ethnocultural boundaries through their post-secondary and professional orientation experiences, particularly in terms of linguistic choices. The analyses highlight the strengthening of boundaries within Québec's educational institutions and workplaces. The results expose different examples of racism experienced by young adults in their relations with the Québec francophone majority that led them to integrate into English-language post-secondary education and workplaces. In addition, young adults from "black" and "Arabic" minorities more frequently report racist attitudes from francophone Quebecers.

Keywords: ethnocultural boundaries, immigrant-background youth, majority/minority relations, orientation experience.
\end{abstract}

\section{Introduction}

The 1977 Charter of the French Language, commonly known as "Bill 101," provides for compulsory enrolment in French-language public schools for immigrant students up to the end of high school and also promotes francization programs in the workplace (Mc Andrew, 2010). Thus, language issues intensify at the post-secondary level, where students have the freedom to make their own choice of language of instruction, especially in Montréal, where there is a diverse postsecondary market (French- and English-language institutions) (Magnan \& Darchinian, 2014). In addition, the Montréal labour market is characterized by competition between two main languages: English and French (Bélanger et al., 2011; Grenier \& Nadeau, 2011). Linguistic issues in Québec have a macrosocial dimension that is active in post-secondary orientation choices (between English- and French-language institutions) and in professional choices as they relate to languages required in the labour market (Lamarre, 2014). However, in the scientific literature, the transition between post-secondary education and the workplace for immigrant youth has been more focused on rates of post-secondary and labour market access (Kamanzi, 2012; Mc Andrew et al., 2011). Qualitative studies are needed to better understand the sense of discrimination and injustice these young people may experience as they pursue their post-secondary and professional orientation (Carothers \& Parfit, 2017; Lafortune \& Kanouté, 2007; Potvin \& Leclercq, 2014). In Québec, immigrant-background youth experience employment discrimination based on their ethnocultural

\footnotetext{
${ }^{1}$ Dr. Fahimeh Darchinian is an assistant professor at the Université de Montréal (Canada)

Email : fahimeh.darchinian@umontreal.ca

${ }^{2}$ Dr. Marie-Odile Magnan is an associate professor at the Université de Montréal (Canada)

Email : marie-odile.magnan@umontreal.ca
} 
origin (Darchinian, 2018). Statistics show the Québec public service remains predominantly "Québec-born," while immigrants and, in particular, visible minorities are underrepresented (Bouhris et al., 2007). Kamanzi (2012) highlights a high degree of over-qualification for the posts occupied by visible minorities, despite holding Canadian degrees.

Inspired by interculturalism, the Educational Integration and Intercultural Education policy of the Québec Ministry of Education (MEQ) focuses on the importance of teaching students "to participate in social interaction in a democratic, francophone, pluralistic Québec." (1998, p. iv). This policy aims at developing attitudes of openness to ethnocultural, linguistic and religious diversity and the inclusion of pluralism in educational content (Mc Andrew, 2015). The "quest for the identity of Quebecers" (Richard 2009, p. 6) as a separate nation has contributed to an understanding here of multiculturalism as an Anglo-Saxon and Canadian model, to which the Québec model of "interculturalism" is a response. Canadian multiculturalism seeks social cohesion through the meeting of cultures, Québec interculturalism is based on a process of bringing cultural groups together, in which mastery of the French language plays a central role. Both multiculturalism/interculturalism models aim to integrate immigrant populations with the host society and its values. However, in a rhetoric where immigrant populations are considered to have different values than "majority populations" (Bouchard \& Taylor, 2008), the centrality and predominance of the competing francophone and anglophone dichotomies can lead to the normalization of hegemonic cultural values of Canadian or Québec identity (Dhamoon, 2009). According to Dhamoon (2009), while these models have different bases and aims, they are ideologically directed at "the other" through the notion of culture, without paying heed to the "standardized" and homogenized majority identity. This ideology, as conveyed through discourse and policies, has the potential to structure institutional practices in educational institutions and workplaces where the ethnocultural affiliations (language, religion, race, etc.) of immigrant groups are used to alter social relationships (Dhamoon, 2009). In this context, the prevalence of the celebration of diversity through political and media rhetoric masks the need for real antiracist policy (Labelle, 2015; Potvin \& Carr, 2008). The promotion of Québec's identity is fuelled by a sovereigntist discourse - one that can intensify negative attitudes of francophone Quebecers toward immigrants (Breton, 2015). According to Breton (2015), the majority francophone group in Québec feels more threatened by minority groups than does the majority group in the rest of Canada. Studies show that francophone Quebecers tend to categorize immigrants in valued and devalued groups (Berry, 2006): immigrants from France are more valued by the Québec majority than other immigrants (from South America, etc.). This perception may influence intergroup relations in schools since, on the one hand, Québec-born students may be reluctant to form friendships with their peers of (other than French) immigrant origin and, on the other hand, young adult immigrants may react by distancing themselves from majority youth (Steinbach, 2010). In fact, the relationships that immigrant youth develop with the francophone majority can even be confrontational (Darchinian, 2018).

To date, few interpretive studies have focused on the construction of heterogeneous postsecondary orientation experiences of immigrant youth in Québec (Darchinian et al., 2017; Magnan et al., 2015) in relation to the negotiation of ethnocultural boundaries; no study has looked at the structural dimensions of their post-secondary and work experience after entering the labour market.Our qualitative research differs from previous studies, which have looked at the integration of young adult immigrants based on access to post-secondary education and employment. It instead focuses on the experiences of young adults with post-secondary degrees and a job in order to explore from their perspective the structuring of boundaries as they moved through their orientation. Our study is innovative because it takes into account young adults' perceptions of their school experience as they leave the education system and during two years of experience in the 
labour market. Based on the compilation of life stories $(\mathrm{n}=25)$, our study seeks to better understand a posteriori how young immigrant-background adults in Québec who have entered the Montréal labour market negotiate their relations with the Québec francophone majority throughout their postsecondary and professional experiences. Our study focuses on their choices of educational and workplace environments, whether in English and/or French, by closely considering the institutions and the context in order to determine their structural effects on the social relations between minority and majority groups.

The results thus allow us to observe the strengthening of the "majority/minority" boundaries during the process of post-secondary and professional orientation despite Québec policies aimed at developing attitudes of openness to ethnocultural, linguistic and religious diversity (Mc Andrew, 2015). In Québec, the majority group very often defines itself in terms of linguistic identity issues. In many contexts, we thus refer to the "francophone majority" or "francophone Quebecers" as a majority group, demographically and sociologically. In addition, the majority francophone group is sometimes designated with an ethnocultural and racial connotation as "non-immigrant white Quebecers" (Labelle, 2015). When talking about the majority or majority group, our study participants use linguistic, ethnocultural, and racial categorization.

In the following sections, we outline our methodology, which consists of a qualitative exploratory approach using biographical storytelling and typological construction. Next, we present an analytical framework based on relational sociology, which makes it possible to present our results in the form of a typology of majority/minority boundaries.

\section{Methodological Approach}

We have relied on a body of testimonials (Bertaux, 2010) to understand the life experiences of social actors, to get to know the subjective views of individuals on how the objective facts of their journey unfolded (Atkinson, 2007; Demazière, 2003). A total of 25 life stories were solicited from young adults of immigration background. More specifically, the corpus includes 13 young adults who arrived in Québec in high school and 12 who arrived in primary school. We diversified our corpus by age of entry into the system, because the results of empirical studies show that the age of school entry - in primary or secondary - could affect the socio-educational experiences of young immigrants (Kanouté et al., 2008). Indeed, those who were born in the host country (first generation) or arrived at an early age before starting primary school (1.5 generation), through longterm socialization, may be more familiar with the functioning of the education systems and the labour markets of the host countries (Mc Andrew, 2015). Of the 12 young adults who started during elementary school, two were born in Montréal and 10 arrived around the age of five. Of the 25 respondents, two come from Central Africa, one from West Africa, two from North Africa, six from South America, three from East Asia, two from South-East Asia, one from Europe, two from Eastern Europe and six from the Middle East. Of the 25 young adults in the corpus, 21 belong to categories of "visible minorities" as defined by Statistics Canada (2011): two are in the category "Arab" (Algeria, Tunisia); three in the "Southeast Asian" category (Cambodia, Vietnam); six in the "West Asian" category (Iran, Syria); two in the "Latin American" category (Uruguay, Peru); one in the "Chinese" category and seven in the "black" category (Haiti, Congo, Cameroon, Guinea). The four young adults in the corpus who do not belong to the visible minority category are from Russia (1), Moldova (1), Romania (1) and Italy (1).

Chose the 24 to 35 age group because, according to quantitative data, young people from immigrant backgrounds in Canada and Quebec often enter the school system at an older age than their native peers and they experience academic setbacks due to their migration journey or to their 
transition through immigrant-only "welcoming" classes (Mc Andrew, 2015). As a result, they may start and finish their post-secondary education later and start working at an older age than their Canadian-born peers. This grouping made it possible to include people who had, for the most part, completed their CEGEP ${ }^{3}$, undergraduate degree, etc. We did not go beyond 35 years, since we wanted the respondents' memories of their experience with post-secondary language and career orientation to be relatively fresh (Bidart, 2006). With regard to the language choices of the 25 respondents in the corpus, 16 enrolled in a French-language postsecondary institution (CEGEP/university) and nine in an English-language one. As for the language choices in career orientation of the respondents, 10 of them worked in an anglophone environment at the time of the interview, seven in a francophone workplace and eight in a bilingual environment. Biographical interviews lasted, on average, more than two hours each. Their structure was as follows: participants were invited to share their life experiences starting from their parents' migration journey to their experience in the Montréal labour market. It should be noted that the names of the participants cited in this article are pseudonyms.

To begin, we proceeded with a diachronic analysis of the biographical interviews collected in order to place the various events of the participants' lives on a timeline (Atkinson, 2007; Demazière, 2003). We thus developed for each participant a summary sheet which temporally reconstructed, in a before/after sequence, her/his family journey (economic status of the family, parents' rapport with education and with the host society and the majority group, etc.) and her/his post-secondary and career paths (institutions attended, reasons for choice of orientation, interactions with members of the majority group such as peers, colleagues, school stakeholders, employers, and experiences of racism, where appropriate). Thus, we did not immediately adopt an explicit framework based on predetermined themes that would have guided the structure of the analysis of the results. Taking an inductive approach, we immersed ourselves in the field of research in order to detect the emerging themes within the discourse of the respondents (Schnapper, 2012). Themes such as "experienced discrimination" and "majority/minority relationships" thus emerged inductively, which subsequently led us to choose the concept of "boundary" to analyze our results.

\section{Analytical Framework}

The concept of boundaries is relevant for studying the interplay of the actor with power structures and social relations. It is through the implementation of symbolic boundaries in social relations that social boundaries are developed and constructed between different social groups in a society (Alogali, 2018; Ferris, 2019). Social actors, in negotiating social boundaries, do not solely reference their social relationships, they also take into account the structural norms of their society (Carothers, 2018; Lamont \& Molnár 2002; Ritter, 2020). This relational perspective takes into account both the power relationships that structure social relations as well as the impact of negotiations that can temper or reverse power relationships. (Liu \& Emirbayer 2016; Wilcox, 2020). The linguistic orientation of post-secondary and professional pathways is thus defined as a human experience achieved through the negotiation of a complex network of social determinants (Lahire, 2013), power relationships (Lamont \& Molnár, 2002) and social relations (Becker, 2008).

The relational approach allows us to analyze the relationships of racism, perceived and experienced by social actors, as manifested in the dynamics of power relations between majority

\footnotetext{
${ }^{3}$ CEGEP is the French acronym for College of General and Vocational Education. This is the first level of higher education in Québec. A CEGEP diploma provides access to university studies.
} 
and minority groups (Brubaker, 2015; McCorkle, 2020). Indeed, the political powers of host societies can create social boundaries by strengthening symbolic boundaries, in particular, religion and language, between immigrants and members of the host society (Lamont \& Molnár, 2002). Educational systems and the labour market of host countries, by favouring the majority group, which is already advantaged by the fact it is "white," contribute to institutionalizing different types of discrimination (Van Dijk, 1993; Robbins et al., 2019) such as ethnicism, ethnonationalism, religious intolerance and racism (Bourhis et al., 2007). Minority groups may belong to linguistic groups other than the majority group. When discrimination is directed at an outsider racial group, it is referred to as racism, and when it is directed at a minority linguistic group, it is referred to as linguicism (Jost \& Major, 2001; Tarman, 2018). In the context of this study, the majority group is white francophone Quebecers of non-immigrant background. The minority groups studied are Québec residents who were either born outside of Canada (1st generation), in Canada (2nd generation), or arrived at an early age before starting primary school. (1.5 generation) (Mc Andrew, 2015).

In order to study the process of moving back and forth between symbolic and social boundaries, we have conceptualized the analytical strategies proposed by Lamont \& Molnár (2002). The analyses thus focus on certain boundary characteristics, such as "visibility," "durability," "permeability" and "salience" as well as addressing the social conditions under which these types of boundaries take shape (p. 186);1) "visibility" can designate social boundaries in which ethnocultural differences manifest themselves in such a way that the minority gradually becomes aware of the existence of majority/minority boundaries; 2) "permeability" can designate social boundaries through which the minority group can establish harmonious relations with the majority group and the host society; the minority perceives that its ethnocultural affiliations are respected by the majority and by the structural norms of society; 3 ) "durability" can represent social boundaries in which the minority group maintains its distance from the majority group over a long time frame, while avoiding conflicting relationships; in this case, the minority tends to create a social world in which the majority is absent; 4) "salience" designates boundaries that grow stronger over time, becoming increasingly insurmountable; the minority feels rejected and develops conflicting relations with the majority. Using this conceptualization, the study aims to describe the dynamics of the majority/minority boundaries in the process of post-secondary and vocational orientation of young adults of immigrant background. It also aims to describe how these young adults negotiate these boundaries.

\section{Typology of Majority/Minority Boundaries}

The analyses led us towards the identification of five typology of majority/minority boundaries: 1) tangible boundaries; 3) permeable boundaries; 4) fading boundaries; 2) sustained boundaries; and 5) hardening boundaries. For each type, specific post-secondary and career experiences were classified. It should be noted that young adults in the corpus may experience several types of boundaries. Indeed, it turns out that the experience of boundaries varies according to different periods of the orientation process: the transition from secondary to post-secondary education, the post-secondary period, the transition from the post-secondary to the labour market and period in the labour market. 


\section{Tangible Boundaries}

Seven cases fit this typology, illustrating the "visibility" of social boundaries between majority and minority groups such that, because of highlighted ethnocultural differences, the minority becomes aware of the boundaries separating it from the majority group. As a result, the minority realizes that ethnocultural categorization has a tangible effect on its social relations. This typology represents young adults in the corpus whose experiences of relationships with the majority group reveal a concretization of majority/minority boundaries, more specifically at the time of entry to post-secondary education in CEGEP. It appears that the transition to postsecondary education is an important time in the negotiation of majority/minority boundaries by young adults in this classification. These young adults tend to keep their distance from the majority group. It appears the symbolic boundaries separating them and the majority group, rooted in reified ethnocultural differences, take concrete form. In other words, during and following the transition to post-secondary education (CEGEP), ethnocultural boundaries that had had a more abstract nature are transformed into more concrete and visible interactive social boundaries. This typology includes three types of post-secondary orientation or reorientation: from secondary school to French-language CEGEP, from French-language CEGEP to French-language university, and from French-language university to the English-language workplace.

Young adults in this typology generally have French as their mother tongue. Consistent with their language of secondary education, they tend to orient themselves to the francophone postsecondary sector. The representations developed by these young adults about francophone Quebecers who are not immigrants paint a portrait of a relationship under stress. Take the example of Stim, a young man of Cameroonian origin, whose stories of relationships (both in and out of school) with francophone Quebecers highlight his experience of racism during his time at a Frenchlanguage CEGEP:

I have the feeling that Québec teachers prefer Québec students. They wanted to hide it, but couldn't, so it was obvious, like how I had a teacher for whom we had to do a project, and we managed to do the project but, because, because there was often a CEGEP policy that if you miss 15 percent ... of your classes, the teachers can make you, like, fail the course and take it over, but you can miss 15 per cent and pass your exams. So there were teachers who said, yes, like, it's okay as long as you pass the course, etc. Then, when you get your marks you see that they gave you 50 in all subjects precisely because of the absences, when they had told you that it would be okay. With Quebecers, I didn't dare ask, but I felt like it wasn't like that, they got along with each other, you know, things like that .... (Stim, Cameroon)

Despite this, Stim enrolled in a French-language university after CEGEP. However, when he reached the professional integration stage, he turned to the anglophone labour market. In general, these young adults' relationships with francophone Quebecers distances them farther from the majority group. Amal, a Muslim woman from Syria, turned to a French-language university after her French CEGEP, because the program she wanted was offered at that university. Amal feels that she did everything she could to feel integrated in that environment, but it was impossible:

So I said, 'I'm going to make friends, ' the first week, you know, to keep morale up, because it's like a very tight-knit program, there were plenty 
of activities for new students and they were all drinking activities and I don't drink. Well, I went to the first activity, I encouraged people, but I didn't drink, so I went to the next activity, I went to the third activity, but I didn't feel like I was connecting with people anyway, no one started a friendship. What I was doing was I was getting my stuff and then I was going downtown, and I was studying at the Concordia [English-language university] library, and I felt comfortable there, and there I had friends and I was making friends and I remember, people came over to see me and they saw that I had civil codes, criminal codes, things like that on my table and, 'but you study law?' 'Yes.' 'But Concordia doesn't have a law program.' I said, 'yes, I am at the UdeM," and everyone thought I was going to Concordia as a student. [Concordia] is just colourful, in Montréal it's just a more diverse environment where you don't feel like the immigrant, you feel like everyone else, while in the UdeM I felt like the immigrant. (Amal, Syria)

Thus, the type of boundaries that become tangible highlights the transformation of symbolic ethnocultural boundaries perceived in an abstract way in high school to visible majority/minority boundaries lived concretely in relationships, especially at the start of CEGEP and during college studies.

\section{Permeable Boundaries}

Four cases fit this typology, illustrating the "permeability" of social boundaries between the majority and minority groups. These are the social boundaries around which minority groups are able to establish harmonious relations with the majority group, because the minority perceives that its ethnocultural affiliations are respected by the majority group and in societal policies and norms. These young adults tend to include francophone Quebecers in their network of friends, which reveals a lack of conflict experiences or strained power relations:

It was my friends who adapted more to me, my Québec friends. My Québec friends, when they came to our place, they took off their shoes, they said hello to my parents in my language, they had learned that, things like that, they had even learned other Persian words, like they were coming home... (Elnaz, Iran)

This typology represents the following types of post-secondary linguistic orientation and reorientation: French-language CEGEP and university; and English-language university and CEGEP.

The orientation toward francophone post-secondary environments (CEGEP and university) is the result of permeable boundaries that allow these young adults to opt for a French-language university after doing CEGEP in French. These young adults do not identify with the majority group, but they tend to develop harmonious relationships with it. Marina, originally from Russia, shows a sense of attachment to the French language, but not necessarily to Québec culture. She has many Québec friends because she feels more comfortable communicating in French than in Russian or English: 
My friends and I spoke French all the time, so we said... everyone just said, "we're going to go to a francophone CEGEP." That's it, and then the one that was closest to me was Gérald Godin CEGEP. So that's where I went; we never had any debates about that. For me, speaking French, learning French has a value. So I always wanted to study in a francophone institution. For the moment, I identify myself as a student, let's say, at the UdeM in the teaching of French in high school. I come from Russia, but I feel a bit like a Quebecer in my mentality, but of course my origins are Russian, I could never say I'm totally a Québecer. Quebecers are different. (Marina, Russia)

The orientation toward anglophone post-secondary environments is also consistent with the type of boundaries that are permeated along the pathway. To illustrate this type, let us take the example of Frank, from China, and Jimmy, from Italy; they both went to English-language universities after attending college in English. The story of Frank, who is originally from China, highlights the development of his harmonious relationship with the majority group even as he moves toward the anglophone post-secondary and professional communities:

Francophones are nicer. The French are nicer, once you speak French with them, they are your friend. But the English are more arrogant. Anglophones, perhaps not in Montréal, but in the other provinces, are more arrogant. I don't understand that, I don't like people speaking only French or only English. I'm an immigrant, I speak both. I like people who want to speak both languages. (Frank, China)

Thus, the permeability of the majority/minority boundaries is illustrated in the experience of orientation toward francophone communities from CEGEP to the labour market, as well as in the experiences of orientation toward anglophone post-secondary and professional environments. However, the boundaries between the minority and the majority seem to be built and transformed at the crossroads of power relations (Juteau, 2015; Zolberg \& Woon, 1999) and negotiation (Liu \& Emirbayer, 2016).

\section{Fading Boundaries}

Two cases fall within this typology, which also illustrates the "permeability" of social boundaries between the majority and minority groups. However, here it appears that the process through which majority/minority boundaries permeate is at its peak, illustrating a process of minority group members identifying with the majority group. In other words, the symbolic boundaries between these two groups do not result in majority/minority social boundaries. This typology includes two young Cambodian women who arrived in Québec before starting primary school. They have never experienced racism in their relations with the majority group. They identify themselves as francophone Quebecers at the end of high school. They reflect the language and culture of the majority group without necessarily forgetting their roots. That French was the first language they learned and developed seems to have played an important role in the identification process. Moreover, their parents, having a low level of schooling, did not have the necessary skills to be involved in the orientation of their academic education. In other words, they were mainly supported by the school and its resources (Kanouté et al., 2008). This typology 
includes the following types of orientation: French-language CEGEP, university and the labour market; and reorientation from English-language CEGEP toward the French-language university.

To illustrate the fading boundary typology, let's take the example of Shima. This young woman went to a French-language university after her French-language CEGEP and worked in a francophone environment at the time of the interview. She points out that she has always had a constructive relationship with Quebecers in her school and out-of-school experiences. She believes that French should be the common language of Québec:

The Indians, the Romanians, the Iranians, they get here and they already speak English. So, either you say that, okay, you want to immigrate to North America, and North America is anglophone, or you say that you chose to immigrate to Québec. The difference between Québec and North America is French. Here, you must learn French. I don't consider that learning French is a shortcoming. For me, learning French is essential. I am a francophone Quebecer; I have been since high school. (Shima, Cambodia)

For this typology, the fading boundaries can be seen in the successive francophone linguistic orientation experiences in post-secondary and professional environments. However, this typology is also found in linguistic orientation experiences going from anglophone post-secondary to francophone post-secondary environments. The case of Yuma, also from Cambodia, highlights this type of fading-boundary orientation experience. With strong aspirations for her future, she went to an English-language CEGEP after high school. Her experience in English-language postsecondary education strengthened her sense of attachment to the francophone majority group. She interprets her experience in English as unpleasant. In fact, she "counted the days until I again found myself among French-speaking Quebecers" (Yuma, Cambodia).

\section{Sustained Boundaries}

Five cases fit this typology, which illustrates the "durability" of social boundaries between the majority and minority groups, so that the minority constantly maintains its distance from the majority over a long time frame. The minority thus tends to create a social world free of the majority. This typology highlights boundaries that do not become harder or more permeable over time, but which persist. Thus, this type of boundary includes young adults for whom the perception of the majority group does not change greatly between secondary education and the labour market. In fact, the boundaries become fixed during secondary school and do not become more or less visible afterward.

Some of these young adults have been exposed to both an inclusive and an exclusive attitude of the majority group. Some of them experienced racism and religious intolerance, others have not. This reveals the heterogeneity of human experience in a given context resulting from the diversity of actors involved (Abbott, 2005). Others have witnessed racism against other immigrant youth, although they have not experienced it directly. In general, young adults of this typology want to leave Québec to live in a different society because they lack attachment to the majority group. It should be noted that these young adults may have had a long history of relationships with members of the majority group in their conjugal lives, or even have Québec spouses. However, this long-term relationship - which often allows them to join a broader social network of francophone Quebecers - does not promote the permeability of the majority/minority boundaries among these 
young people. This typology includes the following types of post-secondary and vocational linguistic orientation: to French-language CEGEP and university and francophone or bilingual labour market; and English-language CEGEP, university and labour market.

Many young adults with diverse ethnocultural backgrounds and family characteristics share a tendency to want to "be careful in my dealings with Quebecers" and "keep my distance" since "francophone Quebecers are unpredictable and we can't know when they like you and when they don't." (Sylvia, Romania). Let's take the example of Lucia, from Uruguay, who went to Frenchlanguage CEGEP and the university after high school. Her university program - teaching French as a second language - naturally directed her to francophone workplaces. She had good Québec friends, but she always tended to find friends among Spanish speakers, with whom she felt more comfortable. When she recounts her story of relationships with the majority group, she often feels a sort of sadness. She both likes and dislikes what she has accomplished throughout her linguistic post-secondary and career orientation. Thus, it seems that consistent French-language orientation from CEGEP to the labour market does not translate into permeability of the majority/minority boundaries. Her orientation process illustrates sustained boundaries between immigrant youth and francophone Quebecers. Lucia wishes to return to Uruguay and live a few years there:

I had Québec friends in CEGEP. I am still friends with them today, but I never had close Québec friends! In fact, I don't want to have close Québec friends. That's right. I think that although I met people, Quebecers, who were open-minded, I didn't feel discriminated against, but I could see that the teachers did not like some students. My mother talked about her Québec colleagues, too, that were not very welcoming toward her. Look, listen, anyway, I could not trust them. [When] I was young and I liked a Québecer, I even had a relationship with him, but no, it didn't work for me. I didn't feel good around his friends and family, so, so far, it's been an obstacle. That's it, it seems like a vicious cycle. (Lucia, Uruguay)

In this typology, where we observe the durability of majority/minority boundaries, we may also see young adults from immigrant background who have turned to English-language postsecondary and professional environments after high school in French. It seems the parents of these young people often have a highly stressed relationship with Québec's societal norms and, more specifically, with its policies. These young adults, shaped by their experiences with racism, have had a stressed relationship with the majority group since childhood and adolescence. They have almost no Québec friends and explain that they do not embrace the values of the majority group. It seems that they have created a sort of immigrant society within Québec society. In explaining their relations with francophone Quebecers, they tend to maintain boundaries with them. This group of young people stress that Québec's language policies come "at the expense of young immigrants."

I find Quebecers, not all of them, but most of them, are not very open, they hate immigrants a little, immigrants irritate them. It is really their leaders who have chosen to let immigrants in. I was never very close, I had friends from all the other countries, but never Quebecers. I don't know why, we never had any affinity, which is unfortunate, I find. Besides, I don't want to generalize again, but the people I met ... no, I never had a boyfriend who was a Quebecer, I never had any interaction 
with someone who is a Quebecer. Colleagues yes, but it never went too far, I mean, it was just professional." (Sylvia, Romania)

For these young adults, the language orientation pathways from English-language CEGEP to the anglophone labour market mark the durability of the majority/minority boundaries. The distancing of immigrant groups from the majority group is reflected here in the Othering of the "Them/Us" relationship and lived experiences of racism (Collins \& Bilge, 2016; Delphy, 2008).

\section{Hardening Boundaries}

Seven cases are consistent with this typology of "salient" social boundaries between the majority and minority groups. These are boundaries that strengthen over time, becoming more and more impassable. This type of boundary highlights the tense relationship that young adults in the corpus maintain with the majority group: young minority-background adults who feel rejected by the majority group. The stories these young adults tell of their relationships with the majority group allow us to observe the intensity of power relations at the heart of relational dynamics. The relationship of these young adults with the majority group is stressed. Generally speaking, they question the norms of the host society, such as language policies, the Québec Charter of Values and the Quebec sovereignty project. This type of boundary more clearly highlights the tendency to move toward anglophone communities because of the experience of racism linked to linguicism and religious intolerance. It includes the following types of paths: "orientation to anglophone workplaces" and "reorientation to English-language post-secondary education."

This type of majority/minority boundary is illustrated in the experience of orientation toward anglophone workplaces. Respondents who are in this category - those who turn to anglophone workplaces - are mostly from Franco-colonial countries, including young people with French as their mother tongue. They also belong to the visible minority category. The experience of racism in interaction with religious intolerance seems to encourage these young adults to eschew francophone workplaces that they consider to be the seat of Quebecers' power. Since they perceive anglophone workplaces to be less discriminatory, they prefer to be part of those environments. Tiam's stories of her relationship with francophone Quebecers illustrate this category of majority/minority boundaries. Originally from Guinea, Tiam pursued all her post-secondary education in the French-language sector. However, she oriented toward an English-language workplace. Tiam's testimonial highlights the experience of racism and her determination to not work in a francophone environment:

I was told by patients, 'I don't want a black person to touch me.' I worked at the Saint Luc Hospital as an orderly, and I had six weeks of training. The guy who trained me, he sat down at the station and did nothing. He gave me the heaviest cases and told the patient to write down whether I did a good job or not. So I felt watched, I felt stalked. When you're black, when you're an immigrant, and you talk, it's doubly scary. I had a friend who told me you need to go to the Jewish Hospital, you're gonna be fine at the Jewish Hospital. In an anglophone hospital, it's more liberal, people are more open, there are a lot of immigrants, and it doesn't work the same. I went over to the anglophone milieu and I have been working there ever since. Racism also exists in the Englishspeaking community, I mean, but the relationship to racism is different, 
it's more violent in the francophone community than in the anglophone community. It is more direct in the francophone community than in the anglophone community (Tiam, Guinea).

Thus, a strong sense of exclusion is developing among young francophone visible minority adults who fall into the category of "hardening boundaries." The negotiation of this boundary seems to direct these minority youth to anglophone workplaces. The experience of reorientation from the francophone post-secondary environment toward an anglophone post-secondary one also illustrates the hardening of boundaries. The linguicism experienced in French-language CEGEPs - which can be combined with racism related to religion - seems to push respondents in this category to anglophone post-secondary environments. These respondents view the language standards (losing marks based on the number of French errors) in francophone post-secondary environments as discriminatory. Thus, after transitioning to anglophone post-secondary environments, these young adults often continue their university studies in English settings and are also directed toward anglophone workplaces. It seems other experiences they have had with francophone Quebecers in different social contexts solidify their negative perception of the majority group. In the case of Rose, from Haiti and Sabri, a Muslim woman from Syria, postsecondary and vocational orientation to anglophone communities is the result of the experience of linguicism combined with the experience of racism in French-language post-secondary education (CEGEP).

In French CEGEP, you'll lose a lot of marks if you make [language] mistakes. In English, you're not going to lose the marks, so you can get a good average, a good $R$-score to later choose your program in university. It hurts me to say this, but francophones are very racist. Anglophones are different towards someone who is young and who is still integrating into society, it was really a very positive experience in the anglophone community and very negative in the francophone community. It is racism when you take away a lot of points for someone who is not a francophone, when she has only been here for three years, and you rate her against someone who was born here and has French as her mother tongue. That is racism, that is to say we will give the better marks to Quebec students, they will have greater hopes, they will have more motivation. I felt suffocated, suffocated, suffocated in my French CEGEP, and in an English-speaking environment, I felt very comfortable, like I'd been liberated (Sabri, Syria).

The case of Mouna, a Muslim woman from Tunisia, makes it possible to observe the experience of religious intolerance in her relations with francophone Quebecers in several spheres of her social life:

Look, the francophone university was not an ideal environment for me with my headscarf. From the moment I wore my scarf, life became difficult for me with Quebecers. Sometimes I was attacked on the streets because people thought I represented Islam. Once, an old lady with her friend, she said to her friend 'look, there goes another one with her handkerchief again,' I said, 'excuse me, madame.' She thought I don't know French. She said, 'Oh, you people are having kids here that are 
going to become like you,' and she attacked me, she attacked me. I was very respectful because of her age, but for a week I cried. For me, the francophone milieu, no, it was over. (Mouna, Tunisia)

These respondents, after reorienting to English-language universities, continue their journey into anglophone workplaces, highlighting their reaction to the uneven power relationships they experienced. Thus, the experience of reorienting from French-language CEGEP towards English-language universities and workplaces falls into the category of boundaries that are hardening as a result of the experience of racism. It turns out that Québec's educational and workplaces systems, by giving priority to the norms of the "whites" of the majority group can contribute to marginalizing immigrant groups whose norms and values are perceived to be inferior (Goldberg, 2006; Mahboob \& Szenes, 2010).

\section{Discussion and Conclusion}

This article sheds new light in the advancement of knowledge regarding the inclusion of immigrant youth in Québec's educational institutions and workplaces. The contribution of our research is to have shown the necessity of going beyond simple statistics of access to diplomas and employment to explain the situation of young immigrants in Québec's educational institutions and the labour market. Our in-depth, qualitative study of the various dimensions of majority/minority relationships has highlighted the processes by which boundaries are maintained or permeated by emphasizing the role of racism, linguicism, religious intolerance and the complex interaction that they arise from in the structuring of the various types of boundaries. Our analyses provide an original contribution in several respects. First, while a few studies in Québec have followed immigrants through to their professional integration, we have interpreted young adults' perceptions of their orientation experience over a longer time frame, from elementary school to entry into the workforce. Second, we have analyzed the development (or lack thereof) of social relations of race as an essential dimension of the permeability of boundaries through post-secondary and vocational orientation. Third, the five typologies of boundaries identified in relation to post-secondary and career orientation experiences - in terms of language (choice of francophone or anglophone postsecondary institutions or workplaces) - show that the climate of institutions perceived as inclusive or exclusive plays a more important role in the choice process than mother tongue and/or the linguistic structure of the labour market.

Among the 25 young adults in the study, the testimony of only six (one-quarter of the corpus) illustrates the permeability of boundaries; yet despite this, these six young adults did not necessarily turn to francophone post-secondary education or workplaces. The testimonies of 19 young adults (more than two-thirds) of their experiences in dealing with the majority group suggest the resilience of the majority/minority boundaries. More specifically, at the labour-market orientation stage, the majority of these young adults, especially those classified as visible (black and Arab minorities, especially Muslim women in the corpus) are oriented toward anglophone workplaces. In addition, those who turned to francophone workplaces at the time of the interview mentioned a desire to reorient to anglophone workplaces. The rather stressed relationship that 19 of the young adults have with the francophone majority group in Québec reflects the findings of various studies: that white francophone Quebecers are more likely to develop negative attitudes toward immigrants (Berry, 2006; Breton, 2015) under the influence of normative societal discourses that value a normative conception of Québec (Breton, 2015; Labelle, 2015). The results show that the post-secondary and career orientation experience of the young adults we interviewed 
is constructed in relation to the power relationships felt vis-à-vis the majority group (Juteau, 2015). However, the orientation experience of six young adults, mainly from Cambodia and China, who have rather a harmonious relationship with the majority group, suggests that social relationships are not always alienated from domination relationships (Abbott, 2005; LaPaglia, 2018). It thus seems permeable boundaries are not related to assimilation by the Quebec francophone majority group but rather to a fellowship in diversity. It should be pointed out that these young adults did not necessarily arrive here at primary school age. In fact, having had long-term socialization does not seem to explain the development of this harmonious relationship, at least for our corpus (Mc Andrew, 2015). Rather, it is the absence of self-reported experiences of racism that seems to positively shape their perception of francophone Quebecers.

The results of this study help to capture the intersectionality of linguicism, racism and religious intolerance in the discourse of young adults (Collins \& Bilge, 2016) in the creation of the boundaries between the majority and the minority. This has allowed us to glimpse how a culturalist ideology - dominant in western host societies - by reducing ethnocultural affiliations of immigrant groups to the static categories of language and religion, helps to maintain power relations (Brubaker, 2013). Thanks to the contextualization of orientation experiences, the analysis reveals that the normative discourses of society as well as the discourses around an exclusive Québec identity can not only shape the reciprocal perceptions of minority groups and the majority group, but also encourage the majority group to discriminate against minorities (Brubaker, 2013; Labelle, 2015). This dynamic could hinder the permeability of the majority/minority boundaries and the "living together" objectives in Québec policies. Interculturalism in Québec, explicitly named in the Policy on Inclusive Schooling and Intercultural Education (Labelle, 2015), does not seem to transcend the day-to-day interactions as perceived and experienced by the young immigrant adults we interviewed.

It should be noted, however, that the analyses were taken from a corpus of 25 interviews conducted in Montréal. Therefore, they may not be representative of the study populations. However, the analyses make it possible to formulate hypotheses and avenues to be explored. From this perspective, we believe it may be appropriate to conduct further research on specific groups of visible minorities in order to corroborate or refute the results found in our corpus. The particularity of the experiences of young adults from Cambodia and China, situated in the typology of permeable boundaries, raises the question of whether it is their ethnic characteristics which explain their tendency to develop harmonious relationships with the majority group (James, 2018; Ho, 2014) or if it is the positive stereotypes maintained by the majority group towards these groups that prevent the emergence of conflicting relationships (Shih et al., 2019). This observation makes it possible to identify avenues of research aimed at making the social reality of young people from East Asia and Southeast Asia more visible in host societies. Interviews should also be conducted with young adults in the majority group. A comparison between the testimonies of these two groups would enrich the analysis. By giving voice to young adults in the majority group, we could discover different types of attitudes and different types of actors. This would make it possible to understand societal norms that promote racial social rapport. As part of our study, we have dug more deeply into the evolution of these boundaries from secondary school to the labour market entry. The analysis of transformations of the different typologies of majority/minority boundaries over a longer time frame is a relevant line of research. Given that the linguistic orientation of postsecondary and workplace training takes on a specific meaning in the Québec context, it would be appropriate to conduct comparative analyses with other Canadian provinces where language issues and power relations are articulated differently. 


\section{Funding Details}

This article is founded on the results of Fahimeh Darchinian's doctoral research at the Université de Montréal. The study was not funded or sponsored by any organization.

\section{Disclosure Statement}

The authors declared no potential conflict of interest with respect to the research, authorship and/or publication of this article.

\section{References}

Abbott, A. (2005). Ecologies and fields. University of Chicago. Retrieved May 10, 2016, from http://home.uchicago.edu/aabbott/Papers/BOURD.pdf

Alogali, A. (2018). World Englishes: Changing the Paradigm of Linguistic Diversity in Global Academia. Research in Social Sciences and Technology, 3(1), 54-73. https://doi.org/10.46303/ressat.03.01.4

Atkinson, R. (2007). The life story interview as a bridge in narrative inquiry. In D. J. Clandinin (ed.), Handbook of narrative inquiry: Mapping a methodology. Thousand Oaks, CA, US: Sage Publications, Inc, 224-245.

Becker, H. S. (2008). Outsiders. New York, Simon \& Schuster.

Bélanger, A., Sabourin, P. \& Lachapelle, R. (2011). Une analyse des déterminants de la mobilité linguistique intergénérationnelle des immigrants allophones au Québec (An analysis of the determinants of intergenerational linguistic mobility of allophone immigrants in Québec). Cahiers québécois de démographie, 40(1), 113-138. https://doi.org/10.7202/1006634ar

Berry, J. W. (2006). Mutual attitudes among immigrants and ethnocultural groups in Canada. International Journal of Intercultural Relations, 30(6), 719-734. DOI:10.1016/j.ijintrel.2006.06.004

Bertaux, D. (2010). Life Stories. Paris, Armand Colin.

Bidart, C. (2006). Crises, décisions et temporalités: Autour des bifurcations biographiques (Crises, decisions and temporality: Around biographical bifurcations). Cahiers internationaux de sociologie, 1(120), 29-57.

Bouchard, G. \& Taylor, C. (2008). Building the future: A time for reconciliation. Government of Québec: Consultation Commission on Accommodation Practices Related to Cultural Differences.

Bourhis, R. Y., Montreuil, A., Helly, D. \& Jantzen, L. (2007). Discrimination et linguicisme au Québec: Enquête sur la diversité ethnique au Canada (Discrimination and linguicism in Quebec: Survey on ethnic diversity in Canada). Canadian Ethnic Studies, 39(1-2), 31-49. https://doi.org/10.1353/ces.0.0001

Breton, C. (2015). Making national identity salient: Impact on attitudes toward immigration and multiculturalism. Canadian Journal of Political Science/Revue canadienne de science politique, 48(2), 357-381. DOI:10.1017/S0008423915000268

Brubaker, R. (2013). Language, religion and the politics of difference. Nations and Nationalism, 19(1), 1-20. DOI: 10.1111/j.1469-8129.2012.00562.x

Brubaker, R. (2015). Linguistic and religious pluralism: Between difference and inequality. Journal of Ethnic and Migration Studies, 41(1), 3-32. https://doi.org/10.1080/1369183X.2014.925391 
Carothers, D., \& Parfitt, C. M. (2017). Disability or Language Difference: How Do We Decide?. American Journal of Qualitative Research, 1(1), 1-12.

Carothers, D. (2018). A culture of equality?. Journal of Culture and Values in Education, 1(2), 4257. https://doi.org/10.46303/jcve.01.02.3

Collins, P. H., \& Bilge, S. (2016). Intersectionality. New York, NY: Wiley.

Darchinian, F. (2018). Les parcours d'orientation linguistique postsecondaire et professionnelle: L'expérience de jeunes adultes issus de l'immigration à Montréal (Post-secondary and vocational linguistic career paths: The experience of young adults of immigrant background in Montreal). Montréal : doctoral thesis presented at the Universite de Montréal.

Open. https://papyrus.bib.umontreal.ca/xmlui/bitstream/handle/1866/20057/Darchinian_Fahime h_2018_these.pdf?sequence=2

Darchinina, F., Magnan, M-O. \& Kanouté, F. (2017). Jeunes adultes québécois issus de l'immigration et rapport au marché du travail: Logiques d'orientation professionnelle (Young Quebec adults from an immigrant background and the labour market: Vocational orientation reasoning). Diversité Urbaine, 17, 113-132. https://doi.org/10.7202/1047980ar

Delphy, C. (2008). Classer, dominer (Classify, dominate). Paris: La Fabrique.

Demazière, D. (2003). Matériaux qualitatifs et perspective longitudinale: La temporalité des parcours professionnels saisis par les entretiens biographiques (Qualitative material and longitudinal perspective: The temporality of professional pathways captured through biographical interviews). Céreq Documents Séminaires, 171, 75-89.

Dhamoon, R. (2009). Identity/difference politics: How difference is produced and why it matters. Vancouver: UBC Press.

Ferris, E. (2019). Lessons of Policing and Exclusion. Journal of Culture and Values in Education, 2(3), 25-43. https://doi.org/10.46303/jcve.03.02.2

Goldberg, D. T. (2006). Racial europeanization. Ethnic and Racial Studies, 29(2), 331-64. https://doi.org/10.1080/01419870500465611

Grenier, G., \& Nadeau, S. (2011). Immigrant access to work in Montreal and Toronto. Canadian Journal of Regional Science, 34(1), 19-32.

Ho, R. (2014). Do all Asians look alike?: Asian Canadians as model minorities. Studies on Asia, 4(2), 78-107.

James, G. (2018). A narrative inquiry perspective into coping mechanisms of international postgraduate students' transition experiences. American Journal of Qualitative Research, 2(1), 41-56.

Jost, J. T. \& Major, B. (2001). The psychology of legitimacy: Emerging perspectives on ideology, justice, and intergroup relations. Cambridge: Cambridge University Press.

Juteau, D. (2015). L'ethnicité et ses frontières (Ethnicity and its boundaries) (2 ${ }^{\text {nd }}$ ed.). Montréal, Les Presses de l'Université de Montréal.

Kamanzi, P. C. (2012). L'emprise des titres scolaires sur l'emploi chez les membres de minorités visibles: Comparaison entre le Québec et l'Ontario (The influence of educational qualifications on employment among members of visible minorities: Comparison between Quebec and Ontario. Recherches sociographiques, 53(2), 315-336. https://doi.org/10.7202/1012403ar

Kanouté, F., Vatz Laaroussi, M., Rachédi, L. \& Tchimou Doffouchi, M. (2008). Familles et réussite scolaire d'élèves immigrants du secondaire (Families and academic success of immigrant students in high school). Revue des sciences de l'éducation, 34(2), 265-289. https://doi.org/10.7202/019681ar 
Labelle, M. (2015). Multiculturalisme, interculturalisme, antiracisme: Le traitement de l'altérité (Multiculturalism, interculturalism, anti-racism: The treatment of otherness). Revue européenne des migrations internationales, 31(2), 31-54. https://doi.org/10.4000/remi.7255

Lafortune, G. \& Kanouté, F. (2007). Vécu identitaire d'élèves de $1^{\text {ère }}$ et de $2^{\mathrm{e}}$ génération d'origine haïtienne (Identity-related experience of $1^{\text {st }}$ and 2 nd generation students of Haitian origin). Revue de l'Université de Moncton, 38(2), 33-71. https://doi.org/10.7202/038490ar

Lahire, B. (2013). Dans les plis singuliers du social: Individus, institutions, socialisations (In the unique folds of social tissue: Individuals, institutions, socialization). Paris, La Découverte.

Lamarre, P. (2014). Bilingual winks and bilingual wordplay in Montreal's linguistic landscape. International Journal of the Sociology of Language, 2014(228), 131-151. DOI: 10.1515/ijsl-2014-0008

Lamont, M. \& Monlár, V. (2002). The study of boundaries in the social sciences. Annual Review of Sociology, 28, 167-195. DOI: 10.1146/annurev.soc.28.110601.141107

LaPaglia, K. (2018). Book Review: Critical pedagogy: Notes from the real world. American Journal of Qualitative Research, 2(2), 150-153.

Liu, S. \& Emirbayer, M. (2016). Field and ecology. Sociological Theory, 34(1), 62-79. DOI: 10.1177/0735275116632556

Magnan, M. O., Grenier, V., \& Darchinian, F. (2015). Stratégies d'orientation et d'insertion professionnelle des jeunes issus de l'immigration à Montréal: motifs de choix des institutions postsecondaires anglophones et francophones (Orientation and vocational integration strategies for young immigrants from Montreal: reasons for choosing Englishlanguage and French-language postsecondary institutions). Canadian Journal of Sociology, 40(4), 501-526.

Magnan, M.-O. \& Darchinian, F. (2014). Enfants de la Loi 101 et parcours scolaires linguistiques : le récit des jeunes issus de l'immigration à Montréal (Children of Bill 101 and academic linguistic pathways: The story of immigrant-background youth in Montreal). McGill Journal of Education/Revue des sciences de l'éducation de McGill, 49(2). https://doi.org/10.7202/1029425ar

Mahboob, A., \& Szenes, E. (2010). Linguicism and racism in assessment practices in higher education. Linguistics and Human Sciences, 3(3), 325-354. DOI:10.1558/lhs.v3i3.325

Mc Andrew, M. (2010). Les majorités fragiles et l'éducation (Fragile majorities and education). Montréal. Presses de l'Université de Montréal.

Mc Andrew, M. (2015). La réussite éducative des élèves issus de l'immigration: Dix ans de recherche et d'intervention au Québec (The educational success of immigrant-background students: Ten years of research and intervention in Quebec). Montréal, Presses de l'Université de Montréal.

Mc Andrew, M., Garnett, B., Ledent, J. \& Sweet, R. (2011). Les carrières scolaires des jeunes allophones à Montréal, Toronto et Vancouver : une analyse comparative (The academic careers of young allophones in Montreal, Toronto and Vancouver: A comparative analysis). Journal of International Migration and Integration, 12(4), 495-515. DOI: 10.1007/s12134011-0200-X

McCorkle, W.D. (2020). The Relationship Between Teachers' Grade Level and Views on Immigration and Immigrant Students. Journal of Social Studies Education Research, 11(1), 21-41. Retrieved from https://jsser.org/index.php/jsser/article/view/1771

Potvin, M. \& Leclercq, J.-B. (2014). Facteurs affectant la trajectoire scolaire des jeunes de 1624 ans issus de l'immigration en formation générale des adultes (Factors affecting the 
educational trajectory of 16 to 24 year olds from immigrant backgrounds in general adult education). Revue des sciences de l'éducation, 40(2), 309-349. https://doi.org/10.7202/1028423ar

Potvin, M., \& Carr, P. (2008). La 'valeur ajoutée' de l'éducation antiraciste: Conceptualisation et mise en oeuvre au Québec et en Ontario (The "value-added" of anti-racism education: Conceptualization and implementation in Quebec and Ontario). Éducation et francophonie, 36(1), 197-216. https://doi.org/10.7202/018097ar

Quebec Education Ministry (MEQ). (1998). A School for the future: Policy statement on Educational Integration and Intercultural Education. Québec: Government of Québec.

Richard, Louis-André (ed.) (2009). La nation sans la religion? Le défi des ancrages au Québec (Nation without religion? The challenge of anchoring in Quebec). Québec: Les Presses de l’Université Laval.

Ritter, M. (2020). Civility and Shared Fate: Social Studies Teaching as Teaching for Belonging. Journal of Curriculum Studies Research, 2(1), 1-15. https://doi.org/10.46303/jcsr.02.01.1

Robbins, C., Bishop, J., \& Tarman, B. (2019). Against Reactionary Populism: Opening a Needed Conversation in Education. Journal of Culture and Values in Education, 2(3), i-vi. https://doi.org/10.46303/jcve.03.02.ed

Schnapper, D. (2012). Élaborer un type idéal (Creating an ideal type). In L'enquête sociologique (p. 291-310). Presses Universitaires de France.

Shih, K. Y., Chang, T. F., \& Chen, S. Y. (2019). Impacts of the model minority myth on Asian American individuals and families: Social justice and critical race feminist perspectives. Journal of Family Theory \& Review, 11(3), 412-428.

Statistics Canada. Visible minority and population group reference guide, 2011. Ottawa, Government of Canada. Retrieved October 10, 2014. https://www12.statcan.gc.ca/nhsenm/2011/ref/guides/99-010-x/99-010-x2011009-eng.pdf.

Steinbach, M. (2010). Eux autres versus nous autres (Them vs Us): Adolescent students' views on the integration of newcomers. Intercultural Education, 21(6), 535-547. https://doi.org/10.1080/14675986.2010.533035

Tarman, B. (2018). The Awareness of Social Studies Teacher Candidates' Regarding Special Area Competencies and the Overlap Level of These Competencies with Social Studies Degree, Journal of Ethnic and Cultural Studies, 5 (2), 16-28.

Van Dijk, T. A. (1993). Elite discourse and racism. Newbury Park, CA: Sage.

Wilcox, S. (2020). Policy Storms at the Central Office: Conflicting Narratives of Racial Equity and Segregation at School Committee Meetings. Research in Educational Policy and Management, 2(1), 40-56. https://doi.org/10.46303/repam.02.01.3

Zolberg, A. R. et Woon, L. L. (1999). Why Islam is like Spanish: Cultural incorporation in Europe and the United States. Politics \& Society, 27(1), 5-38.

\section{Notes on Contributors}

Fahimeh Darchinian holds a $\mathrm{PhD}$ in Comparative Education (Université de Montréal). Currently, Fahimeh is an assistant professor of Sociology of Education at the Universite de Montréal (Canada). Her main research interests lie in the social relations of racism and the processes of construction of social boundaries in educational institutions.

Marie-Odile Magnan holds a PhD in sociology (Université de Laval.) Currently, MarieOdile is an associate professor of Sociology of Education at the Université de Montréal (Canada). Her main research interests lie in school inequities related to the processes of minorization and racialization in educational institutions and in the practices of inclusive education. 